\title{
Expression levels of microRNA-375 in colorectal carcinoma
}

\author{
XIAONING DAI ${ }^{*}$, YEUNPO CHIANG ${ }^{*}$, ZHENNING WANG, \\ YONGXI SONG, CHONG LU, PENG GAO and HUIMIAN XU
}

Department of Surgical Oncology and General Surgery, The First Hospital of China Medical University, Shenyang, P.R. China

Received November 24, 2011; Accepted February 22, 2012

DOI: $10.3892 / \mathrm{mmr} .2012 .815$

\begin{abstract}
MicroRNAs are small, non-coding RNAs of endogenous origin. They have been increasingly shown to have altered expressions in many cancer types. The expression levels of miR-375 have not been comprehensively investigated in colorectal cancer. In this study, total RNA was extracted from 95 pairs of colorectal cancer tissues and non-tumor adjacent tissues, as well as from three colorectal cancer cell lines (HT-29, HCT-116 and SW-620). After polyadenylation and reverse transcription, we determined the expression levels of miR-375 by real-time PCR and calculated the difference in expression using the $2^{-\Delta \Delta C t}$ method. We assessed the correlation between the expression levels of miR-375 and clinicopathological characteristics of colorectal cancer. miR-375 expression was frequently downregulated in the colorectal cancer tissues compared to the non-tumor counterparts $(\mathrm{p}<0.001$; paired t-test). Moreover, a significantly low expression of miR-375 was also found in the colorectal cancer cell lines (HT-29, $\mathrm{p}=0.002$; HCT-116, p<0.001; SW-620, p=0.004; paired t-test). However, there were no significant correlations between the low expression of miR-375 and tumor size, histological grade, pT stage, $\mathrm{pN}$ stage and pTNM stage (all P>0.05, non-parametric test; Mann-Whitney U test between two groups and Kruskal-Wallis $\mathrm{H}$ test for three or more groups). miR-375 may be involved in the carcinogenesis of colorectal cancers and may be a potential biomarker for colorectal cancers.
\end{abstract}

\section{Introduction}

First discovered in 1993, microRNAs (miRNAs) are an important class of small, endogenously expressed, well conserved, non-coding RNA molecules that post-transcriptionally regulate gene expression. miRNA products are single-stranded RNAs of 19-22 nucleotides cleaved from 70- and 100nucleotide hairpin pre-miRNA precursors $(1,2)$. Due to their

Correspondence to: Dr Zhenning Wang, Department of Surgical Oncology and General Surgery, The First Hospital of China Medical University, Shenyang 110001, P.R. China

E-mail: josieon826@yahoo.com.cn

*Contributed equally

Key words: microRNA, miR-375, colorectal cancer sequence complementarities to the 3'-untranslated region of target mRNAs, miRNAs trigger translational repression or mRNA destabilization and degradation (3). It is currently well established that miRNAs are involved in a broad range of biological activities, such as cellular differentiation, proliferation and apoptosis $(4,5)$. The growing interest in these regulatory miRNAs has led to the continued exploration of miRNA expression in cancer samples and the identification of new miRNAs that may act as oncogenes and tumor suppressors (6). Accumulating studies have shown the dysregulation of miRNA expression in many tumor types, including esophageal squamous cell carcinoma (7), lung cancer (8), breast cancer (9), pancreatic adenocarcinoma (10), hepatocellular carcinoma (11) and gastric cancer (12). Furthermore, it has been reported that miRNA genes are frequently located at fragile sites and genomic regions involved in cancers, suggesting that aberrant miRNA expression may play an important role in cancer pathogenesis (13).

Colorectal cancer is the third most common type of cancer and the third leading cause of cancer-related mortality worldwide. Although the etiology of colorectal cancer is attributed to multiple factors, the accumulation of genetic and epigenetic changes remains the fundamental mechanism of tumorigenesis. In recent studies, the aberrant expression of several miRNAs has been found in colorectal carcinoma. miR-143 is one of the most consistently downregulated miRNAs in colon cancer (14). The miR-143 antagonist increases cultured human colon cancer cell proliferation, whereas miR-143 overexpresssion has an opposite effect (15). Moreover, miR-143 overexpression reduces the colony-forming ability of colon cancer cells in soft agar (16). In our previous study, we revealed that the low expression of miR-148a and miR-152 in 101 colorectal cancer tissues was relative to the matched non-tumor adjacent tissues (NATs) by real-time PCR, and indicated that it was significantly associated with larger tumor size and more advanced pT stage (17).

miR-375 is selectively expressed in pancreatic islets and plays a significant role in insulin secretion regulation $(18,19)$. However, recent studies have shown that miR-375 is frequently downregulated in gastric carcinomas $(14,20)$. The overexpression of miR-375 reduces the viability of gastric carcinoma cells and induces apoptosis, suggesting that miR-375 may be a candidate tumor suppressor miRNA in gastric carcinoma. In our present study, we examined miR-375 expression in 95 colorectal cancer tissues and three colorectal cancer cell lines and found that miR-375 was frequently downregulated in colorectal carcinomas. 


\section{Materials and methods}

Tissues samples. Ninety-five pairs of colorectal cancer tissues and corresponding NATs were obtained from patients who underwent radical resection at the First Hospital of China Medical University (Shenyang, China) between 2007 and 2009, and were subsequently diagnosed with colorectal cancer based on histopathological evaluation. Corresponding NATs were obtained from a segment of the resected specimen that was the farthest distance from the tumor $(>5 \mathrm{~cm})$. Fresh samples were snap-frozen in liquid nitrogen immediately after surgery and were stored at $-80^{\circ} \mathrm{C}$ until use. One section of each sample was stained with H\&E. No previous local or systemic treatment had been conducted on these patients before the surgery. The histological grade of cancers was assessed according to the standards of the World Health Organization. Cancers were classified using the TNM staging system of the American Joint Committee on Cancer (AJCC; 2010) and the International Union against Cancer (UICC). Informed consent was obtained from all patients. The study was approved by the Research Ethics Committee of China Medical University (Shenyang, China).

Cell lines and culture conditions. The human colorectal cancer cell lines (HT-29, HCT-116 and SW-620) were obtained from the Institute of Biochemistry and Cell Biology at the Chinese Academy of Sciences (Shanghai, China). HT-29 and HCT-116 cells were cultured in McCoy's 5a medium (Invitrogen, Carlsbad, CA, USA), and SW-620 was cultured in Leibovitz's L-15 medium (Invitrogen). The normal colorectal tissues (three corresponding NATs) were randomly selected from the 95 cases of colorectal cancer as the controls. All of the cell lines were cultured at $37^{\circ} \mathrm{C}$ and $5 \% \mathrm{CO}_{2}$. The media were supplied with $10 \%$ fetal bovine serum (FBS).

Extraction, polyadenylation and reverse transcriptase reaction. Total RNA was isolated according to the manufacturer's instructions using a mirVana miRNA Isolation kit (Ambion, Austin, TX, USA). The concentration and purity of RNA were controlled by UV spectrophotometry using a NanoPhotometer UV/Vis spectrophotometer (Implen, Schatzbogen, München, Germany).

Escherichia coli poly(A) polymerase (E-PAP) was used for the polyadenylation of total RNA in a $37^{\circ} \mathrm{C}$ water bath for $30 \mathrm{~min}$ following the manufacturer's instructions using the poly(A) Tailing kit (Ambion). RNAs were purified by phenol-chloroform and ethanol after dissolving in diethyl pyrocarbonate (DEPC)-treated water.

Reverse transcription was completed with a SuperScript III First-Strand Synthesis System for a reverse transcriptasepolymerase chain reaction kit (Invitrogen). First, a 10- $\mu 1$ reverse transcriptase reaction mixture containing $1 \mu \mathrm{g}$ of the RNA sample, $1 \mu \mathrm{l}$ RT-primer, $1 \mu \mathrm{l} 10 \mathrm{mM}$ deoxyribonucleotide triphosphate (dNTP) mix and DEPC-treated water was incubated for $5 \mathrm{~min}$ at $65^{\circ} \mathrm{C}$. Then, a $10-\mu 1$ mixture containing $2 \mu 1$ 10X RT buffer, $4 \mu 125 \mathrm{mM} \mathrm{MgCl}_{2}, 2 \mu \mathrm{l} 0.1 \mathrm{M}$ DTT, $1 \mu \mathrm{l}$ RNaseOUT (40 U/ $\mu \mathrm{l})$ and $1 \mu \mathrm{l}$ SuperScript III RT (200 U/ $\mu \mathrm{l})$ was added. The total reaction mixture was incubated in a 96-well plate of a GeneAmp PCR 9700 Thermocycler (Applied Biosystems, Hayward, CA, USA) for $50 \mathrm{~min}$ at $50^{\circ} \mathrm{C}, 5 \mathrm{~min}$ at $85^{\circ} \mathrm{C}$ and $20 \mathrm{~min}$ at $37^{\circ} \mathrm{C}$, after adding $1 \mu 1 \mathrm{RNaseH}$ to the mixture and held at $4^{\circ} \mathrm{C}$.

Real-time PCR. Real-time PCR was performed using the SYBR Premix Ex Taq ${ }^{\mathrm{TM}}$ II kit (Takara Bio, Kyoto, Japan) according to the manufacturer's instructions, with a Rotor-gene 6000 system (Qiagen, Valencia, CA, USA). The 25- $\mu$ l mixture of PCR consisted of $12.5 \mu \mathrm{l}$ SYBR-Green supermix, $8.5 \mu \mathrm{l}$ RNasefree water, $1 \mu \mathrm{l}$ forward primers, $1 \mu \mathrm{l}$ reverse primers and $2 \mu \mathrm{l}$ reverse transcribed product. Threshold cycle data were determined by setting a default threshold. The reactive condition was 45 amplification cycles of $95^{\circ} \mathrm{C}$ for $5 \mathrm{sec}, 58^{\circ} \mathrm{C}$ for $20 \mathrm{sec}$ and $72^{\circ} \mathrm{C}$ for $30 \mathrm{sec}$ in a 36-well optical plate using a Rotor-gene 6000 system. The U6 RNA was adopted as an endogenous reference compared to the expression levels of miR-375, and the $2^{-\Delta \Delta C t}$ method was used to calculate the relative expression levels of miR-375 in cancerous samples compared to their non-tumor counterparts. All samples were performed in triplicate. The products of real-time PCR were confirmed by TA cloning and a sequencing assay. Primers are shown in Table I.

Statistical analysis. We analyzed the expression levels in colorectal cancer tissues relative to non-tumorous controls using the $2^{-\Delta \Delta C t}$ method. First, the threshold cycle $\left(C_{t}\right)$ of fluorescence for each sample was determined. $\Delta \mathrm{C}_{\mathrm{t}}$ indicates the difference in the expression levels with the $\mathrm{C}_{\mathrm{t}}$ value between miR-375 and U6 $\left(\Delta \mathrm{C}_{\mathrm{t}}=\mathrm{C}_{\mathrm{t} \text { miR-375 }}-\mathrm{C}_{\mathrm{t} \mathrm{U} 6}\right)$, and $\Delta \Delta \mathrm{C}_{\mathrm{t}}$ indicates the difference in the $\Delta \mathrm{C}_{\mathrm{t}}$ value between cancer tissue and the corresponding control $\left(\Delta \Delta \mathrm{C}_{\mathrm{t}}=\Delta \mathrm{C}_{\mathrm{tcancer}}-\Delta \mathrm{C}_{\mathrm{t} \text { control }}\right)$. Finally, the $2^{-\Delta \Delta C t}$ value (fold value) was calculated. When the fold value was $<1$, there was a low expression of miR-375 in the cancer tissues and cancer cell lines compared to their non-tumorous counterparts (21). The statistical differences in miR-375 expression in cancer tissues and cell lines relative to NATs were analyzed by a paired t-test. Moreover, the association between miR-375 expression and clinicopathological parameters was analyzed by a non-parametric test (Mann-Whitney U test between two groups and Kruskal-Wallis $\mathrm{H}$ test for three or more groups). $\mathrm{p}<0.05$ was considered to indicate statistically significant differences. Statistical analysis was performed using the Statistical Program for Social Sciences (SPSS) software 16.0 (SPSS Inc., Chicago, IL, USA).

\section{Results}

Expression of miR-375 is frequently downregulated in colorectal cancer tissues. The expression of miR-375 was detected in all 95 pairs of colorectal cancer tissues and their matched NATs by quantitative real-time reverse transcription polymerase chain reaction (qRT-PCR) analysis. The value of $\Delta \mathrm{C}_{\mathrm{t}}$ (mean $\pm \mathrm{SD}$ ) was $6.658 \pm 3.332$ in colorectal cancer tissues and $2.853 \pm 3.401$ in their matched NATs ( $<<0.001$, paired t-test; Fig. 1 ). miR-375 was significantly downregulated in colorectal cancer tissues with a median 16.9-fold reduction relative to their NATs. Among 95 colorectal cancer patients, 68 (71.6\%) cases revealed a $>50 \%$ reduction in the expression levels of miR-375 compared to their corresponding NATs.

Expression of miR-375 is significantly downregulated in colorectal cancer cell lines. To further confirm the asso- 
Table I. RT-PCR primers for amplification of miR-375 expression.

Primer

Primer sequence (5'-3')

RT-primer-1

RT-primer-2

RT-primer-3

miR-375-Forward

miR-375-Reverse

U6 RNA-Forward

U6 RNA-Reverse
GCTGTCAACGATACGCTACGTAACGGCATGACAGTGTTTTTTTTTTTTTTTTTTTTTTTTA GCTGTCAACGATACGCTACGTAACGGCATGACAGTGTTTTTTTTTTTTTTTTTTTTTTTTG GCTGTCAACGATACGCTACGTAACGGCATGACAGTGTTTTTTTTTTTTTTTTTTTTTTTTG TTTGTTCGTTCGGCTCGC GCTGTCAACGATACGCTACGT CGCTTCGGCAGCACATATAC TTCACGAATTTGCGTGTCAT
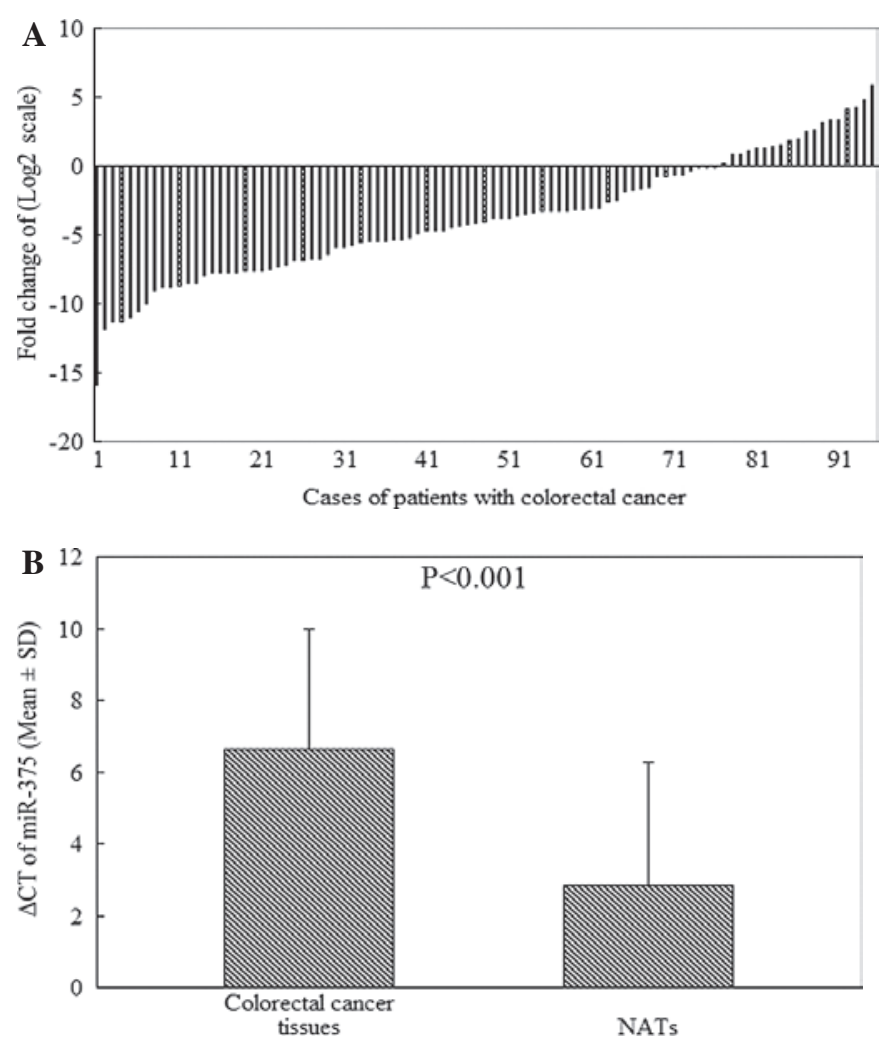

Figure 1. Expression of miR-375 in 95 patients with colorectal cancer. (A) Quantification of miR-375 was measured by SYBR Premix Ex Taq ${ }^{\mathrm{TM}}$ II. Each sample was analyzed in triplicate and repeated three times. Data are presented as the $\log 2$ of fold-change of colorectal cancer tissues relative to matched non-tumor adjacent tissues (NATs). (B) miR-375 was differentially expressed between colorectal cancer tissues and matched NATs. mir-375 was normalized by U6 RNA. $\Delta \mathrm{C}_{\mathrm{t}}=\mathrm{C}_{\mathrm{t} \text { miR-375 }}-\mathrm{C}_{\mathrm{t} \text { U6 RNA }}$. The $\Delta \mathrm{C}_{\mathrm{t}}$ of miR-375 was significantly higher in colorectal cancer tissues than corresponding NATs $(\mathrm{p}<0.001 ; \mathrm{t}$-test $)$.

ciation between miR-375 expression and colorectal cancer, we measured miR-375 expression in three colorectal cancer cell lines using qRT-PCR. We found a significantly low expression of miR-375 in HT-29 cells ( $\mathrm{p}=0.002)$, HCT-116 cells $(\mathrm{p}<0.001)$ and SW-620 cells $(\mathrm{p}=0.004)$ relative to three NATs randomly chosen from the patients (Fig. 2). The fold changes were all $<0.01$.

Correlation between miR-375 expression levels and clinicopathological characteristics in colorectal cancer patients. The non-parametric test between the relative expression levels

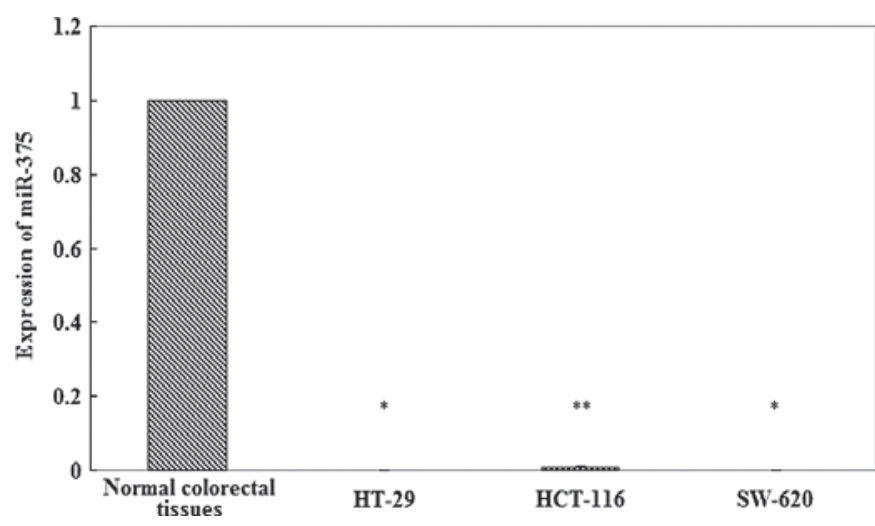

Figure 2. Expression levels of miR-375 in three colorectal cancer cell lines (HT-29, HCT-116 and SW-620). Quantification of miRNAs was measured by SYBR Premix Ex Taq ${ }^{\mathrm{TM}}$ II. Data are presented in colorectal cancer cell lines relative to the normal colorectal tissues. Expression of miR-375 in three colorectal cancer cell lines $\left({ }^{*} \mathrm{p}<0.01,{ }^{* *} \mathrm{p}<0.001\right)$.

of miR-375 in colorectal cancer cases and its clinicopathological features showed that there was no significant correlation between the low expression of miR-375 and gender, age, tumor size, tumor location, histological grade, $\mathrm{pT}$ stage, $\mathrm{pN}$ stage, pTNM stage and lymphatic vessel invasion (Table II).

\section{Discussion}

Previous studies have revealed that miRNA alterations may play a fundamental role in different steps of tumor formation and progression (22). To date, miRNA expression has been studied by cloning and sequencing, northern blotting, in situ hybridization, microarrays, real-time PCR and other techniques. A number of studies have analyzed the global expression pattern of miRNAs in colorectal carcinoma $(23,24)$. However, real-time PCR has an advantage in that it is a more quantitative and more sensitive method compared to those high-throughput assays. Moreover, the results of genome-wide approaches were sometimes affected by the sample numbers. Therefore, we used real-time PCR to assess the expression levels of miR-375 in a large number of cases and clarified the correlation between miR-375 and clinicopathological characteristics in colorectal carcinoma.

miR-375, as a regulator of insulin secretion, is predominantly expressed in pancreatic islets (18). It appears to target myotrophin or 3'-phosphoinositide-dependent protein kinase-1 (PDK1), and inhibits their expression in pancreatic islet 
Table II. Association between the expression of miR-375 with clinicopathological features in patients with colorectal cancer.

\begin{tabular}{|c|c|c|c|}
\hline Colorectal cancer & No. & $\operatorname{miR}-375^{\mathrm{a}}$ & $\mathrm{p}$-value \\
\hline Gender & & & 0.325 \\
\hline Male & 58 & $0.045(0.005-0.597)$ & \\
\hline Female & 37 & $0.103(0.009-0.905)$ & \\
\hline Age (years) & & & 0.162 \\
\hline$\leq 65$ & 57 & $0.092(0.009-1.041)$ & \\
\hline$>65$ & 38 & $0.026(0.005-0.310)$ & \\
\hline Tumor size (cm) & & & 0.322 \\
\hline$<6$ & 66 & $0.079(0.009-0.977)$ & \\
\hline$\geq 6$ & 29 & $0.059(0.004-0.150)$ & \\
\hline Tumor location ${ }^{\mathrm{b}}$ & & & 0.257 \\
\hline Proximal colon & 23 & $0.025(0.006-0.116)$ & \\
\hline Distal colon and rectum & 72 & $0.088(0.008-0.835)$ & \\
\hline Histological grade & & & 0.907 \\
\hline Well/moderately differentiated & 74 & $0.073(0.006-0.903)$ & \\
\hline Poorly differentiated & 21 & $0.059(0.021-0.591)$ & \\
\hline pT stage & & & 0.879 \\
\hline $\mathrm{T} 2$ & 19 & $0.084(0.005-0.593)$ & \\
\hline $\mathrm{T} 3$ & 56 & $0.052(0.007-1.246)$ & \\
\hline $\mathrm{T} 4$ & 20 & $0.107(0.014-0.634)$ & \\
\hline pN stage & & & 0.332 \\
\hline N0 & 60 & $0.074(0.006-0.535)$ & \\
\hline $\mathrm{N} 1$ & 25 & $0.040(0.006-0.763)$ & \\
\hline $\mathrm{N} 2$ & 10 & $0.081(0.025-19.393)$ & \\
\hline pTNM stage & & & 0.809 \\
\hline I & 16 & $0.065(0.005-0.518)$ & \\
\hline II & 42 & $0.083(0.015-0.770)$ & \\
\hline III & 34 & $0.040(0.009-0.994)$ & \\
\hline IV & 3 & $0.010(0.001-0.908)$ & \\
\hline Invasion into lymphatic vessels & & & 0.269 \\
\hline Negative & 86 & $0.069(0.007-0.627)$ & \\
\hline Positive & 9 & $0.054(0.033-18.627)$ & \\
\hline
\end{tabular}

${ }^{a}$ Median of relative expression with 25-75th percentile is recorded in parentheses. ${ }^{b}$ Distal includes tumors located in or distal to the descending colon, sigmoid and rectum. Proximal tumors include tumors in or proximal to the splenic flexure. Statistical significance, $\mathrm{p}<0.05$.

cells $(18,25)$. Studies on miR-375 gene knockout mice have revealed that miR-375 is not only essential for normal glucose homeostasis, but also maintains pancreatic $\alpha$ - and $\beta$-cell mass (26). The targeted inhibition of miR-375 maturation with morpholinos showed that zebrafish miR-375 is essential for the formation of the insulin-secreting pancreatic islet (27).

Take together, it seems that miR-375 is a pancreatic isletspecific miRNA. However, a recent study showed that miR-375 was markedly downregulated in oesophageal squamous cell carcinoma tissues relative to healthy volunteers (28). Furthermore, the downregulation of miR-375 was also found in pancreatic cancer tissues compared to normal tissues (29). In hepatocellular carcinoma of mice, the expression of miR-375 was significantly downregulated and was inversely correlated with the protein levels of Yes-associated protein (YAP), which binds to transcription factors that regulate the transcription of target genes involved in cell growth, proliferation and survival (30). Moreover, Ding et al (31) showed that miR-375 was greatly downregulated in the paired gastric cancer tissues and NATs by microarray. Quantitative real-time PCR analysis verified that miR-375 expression was significantly decreased in more than $90 \%$ of gastric cancer tissues compared to non-tumor counterparts. Notably, they showed that the overexpression of miR-375 reduced the protein levels of Janus kinase 2 (JAK2) and repressed the activity of the 3'-untranslated region of JAK2. Furthermore, Tsukamoto et al (20) indicated that the low expression of miR-375 in gastric carcinoma cells markedly reduced cell viability via the caspase-mediated apoptotic pathway. They found that the overexpression of miR-375 inhibited the expression of PDK1 followed by the suppression of Akt phosphorylation. By contrast, the high expression of miR-375 was found in ER $\alpha$-positive breast cancer cells (32). It has been shown that, compared to normal lung tissues, the expression of miR-375 is significantly upregulated in lung adenocarcinoma 
tissues (33). The upregulated miR-375 was also observed in prostate carcinoma tissues relative to non-tumor prostate tissues (34). The tissue specificity may be one of the reasons for the organ-specific difference in miR-375 expression, as observed for cancer miRNA signatures across different organs of origin (35). Therefore, the expression levels of miR-375 were quite differential in different carcinomas.

To our knowledge, we have performed the largest study to date that assesses the expression levels of miR-375 in colorectal cancers by real-time PCR. We found that miR-375 was frequently downregulated in 95 cancerous and adjacent non-cancerous tissue pairs. Also, the significantly reduced expression of miR-375 was found in three colorectal cancer cell lines. Our results were consistent with previous studies on the global expression pattern of miRNAs in colorectal carcinoma $(23,24)$. Davidson et al $(36)$ showed that the expression levels of miR-375 were dramatically reduced in six rat colon adenocarcinoma tissues compared to six rat normal colon tissues. Therefore, as the low expression of miR-375 is frequently observed in colorectal cancers, it may play a significant role in the process of carcinogenesis. Although there was no significant association between miR-375 expression and clinicopathological characteristics, $71.6 \%$ of cases revealed more than a $50 \%$ reduction in the expression levels of miR-375 compared to their corresponding NATs.

miRNA expression can be reduced by many factors, including transcriptional factors, mutations, deletions and methylation. The mechanism responsible for the downregulation of miR-375 in colorectal carcinoma remains unclear. As the loss at 2q35, wherein miR-375 was located, was found frequently in colorectal cancers (37), it seems possible that allelic loss may be responsible for the downregulation of miR-375. Furthermore, a recent study showed that miR-375 is located in a $\mathrm{CpG}$ island on chromosome 2q35 (National Center for Biotechnology Information) (20). Therefore, it is likely that epigenetic silencing may be responsible for the downregulation of miR-375. Further investigation is required to determine the exact mechanism for the aberrant expression of miR-375 in colorectal cancer.

In this study, we assessed the expression levels of miR-375 in colorectal cancer. Significantly downregulated miR-375 was observed in colorectal cancer tissues and three cancer cell lines relative to NATs. The present study is a basis for further studies on target genes and functions of miR-375 in colorectal cancer. Further large-scale and long-term follow-up studies focusing on the significance of miR-375 in colorectal cancer are currently underway by our group.

\section{Acknowledgements}

This study was supported by the National Science Foundation of China (No. 30873043 and No. 81000943), the Specialized Research Fund for the Doctoral Program of Higher Education (No. 200801590006), and the Natural Science Foundation of Liaoning Province (No. 20092129).

\section{References}

1. Lee R, Feinbaum R and Ambros V: The C-elegans heterochronic gene Lin-4 encodes small RNAs with antisense complementarity to Lin-14. Cell 75: 843-854, 1993.
2. Zeng Y: Principles of micro-RNA production and maturation. Oncogene 25: 6156-6162, 2006.

3. Engels BM and Hutvagner G: Principles and effects of microRNA-mediated post-transcriptional gene regulation. Oncogene 25: 6163-6169, 2006.

4. Stefani G and Slack FJ: Small non-coding RNAs in animal development. Nat Rev Mol Cell Biol 9: 219-230, 2008.

5. Hwang HW and Mendell JT: MicroRNAs in cell proliferation, cell death, and tumorigenesis. Br J Cancer 94: 776-780, 2006.

6. Esquela-Kerscher A and Slack F: Oncomirs - microRNAs with a role in cancer. Nat Rev Cancer 6: 259-269, 2006.

7. Mori Y, Ishiguro H, Kuwabara Y, et al: MicroRNA-21 induces cell proliferation and invasion in esophageal squamous cell carcinoma. Mol Med Report 2: 235-239, 2009.

8. Takamizawa J, Konishi H, Yanagisawa K, et al: Reduced expression of the let-7 microRNAs in human lung cancers in association with shortened postoperative survival. Cancer Res 64: 3753-3756, 2004.

9. Iorio MV, Ferracin M, Liu CG, et al: MicroRNA gene expression deregulation in human breast cancer. Cancer Res 65: 7065-7070, 2005.

10. Ikenaga N, Ohuchida K, Mizumoto K, et al: MicroRNA-203 expression as a new prognostic marker of pancreatic adenocarcinoma. Ann Surg Oncol 17: 3120-3128, 2010.

11. Murakami Y, Yasuda T, Saigo K, et al: Comprehensive analysis of microRNA expression patterns in hepatocellular carcinoma and non-tumorous tissues. Oncogene 25: 2537-2545, 2006.

12. Song YX, Yue ZY, Wang ZN, et al: MicroRNA-148b is frequently down-regulated in gastric cancer and acts as a tumor suppressor by inhibiting cell proliferation. Mol Cancer 10: 1, 2011.

13. Calin GA, Sevignani C, Dumitru CD, et al: Human microRNA genes are frequently located at fragile sites and genomic regions involved in cancers. Proc Natl Acad Sci USA 101: 2999-3004, 2004.

14. Wu W, Law P, Lee C, et al: MicroRNA in colorectal cancer: from benchtop to bedside. Carcinogenesis 32: 247-253, 2011.

15. Chen X, Guo X, Zhang H, et al: Role of miR-143 targeting KRAS in colorectal tumorigenesis. Oncogene 28: 1385-1392, 2009.

16. Ng EK, Tsang WP, Ng SS, et al: MicroRNA-143 targets DNA methyltransferases $3 \mathrm{~A}$ in colorectal cancer. Br J Cancer 101: 699-706, 2009.

17. Chen Y, Song Y, Wang Z, et al: Altered expression of MiR-148a and MiR-152 in gastrointestinal cancers and its clinical significance. J Gastrointest Surg 14: 1170-1179, 2010.

18. Poy MN, Eliasson L, Krutzfeldt J, et al: A pancreatic islet-specific microRNA regulates insulin secretion. Nature 432: 226-230, 2004.

19. Krek A, Grun D, Poy MN, et al: Combinatorial microRNA target predictions. Nat Genet 37: 495-500, 2005.

20. Tsukamoto Y, Nakada C, Noguchi T, et al: MicroRNA-375 is downregulated in gastric carcinomas and regulates cell survival by targeting PDK1 and 14-3-3zeta. Cancer Res 70: 2339-2349, 2010.

21. Chiang Y, Song Y, Wang Z, et al: Aberrant expression of miR-203 and its clinical significance in gastric and colorectal cancers. J Gastrointest Surg 15: 63-70, 2011.

22. Calin GA and Croce CM: MicroRNA signatures in human cancers. Nat Rev Cancer 6: 857-866, 2006.

23. Cummins JM, He YP, Leary RJ, et al: The colorectal microRNAome. Proc Natl Acad Sci USA 103: 3687-3692, 2006.

24. Sarver AL, French AJ, Borralho PM, et al: Human colon cancer profiles show differential microRNA expression depending on mismatch repair status and are characteristic of undifferentiated proliferative states. BMC Cancer 9: 15, 2009.

25. El Ouaamari A, Baroukh N, Martens GA, Lebrun P, Pipeleers D and van Obberghen E: miR-375 targets 3'-phosphoinositidedependent protein kinase-1 and regulates glucose-induced biological responses in pancreatic beta-cells. Diabetes 57: 2708-2717, 2008.

26. Poy MN, Hausser J, Trajkovski M, et al: miR-375 maintains normal pancreatic alpha- and beta-cell mass. Proc Natl Acad Sci USA 106: 5813-5818, 2009.

27. Kloosterman WP, Lagendijk AK, Ketting RF, Moulton JD and Plasterk RHA: Targeted inhibition of miRNA maturation with morpholinos reveals a role for miR-375 in pancreatic islet development. PLoS Biol 5: e203, 2007.

28. Komatsu S, Ichikawa D, Takeshita H, et al: Circulating microRNAs in plasma of patients with oesophageal squamous cell carcinoma. Br J Cancer 105: 104-111, 2011. 
29. LaConti JJ, Shivapurkar N, Preet A, et al: Tissue and serum microRNAs in the Kras (G12D) transgenic animal model and in patients with pancreatic cancer. PLoS One 6: e20687, 2011.

30. Kowalik MA, Saliba C, Pibiri M, et al: Yes-associated protein regulation of adaptive liver enlargement and hepatocellular carcinoma development in mice. Hepatology 53: 2086-2096, 2011

31. Ding L, Xu Y,Zhang W, et al: MiR-375 frequently downregulated in gastric cancer inhibits cell proliferation by targeting JAK2 Cell Res 20: 784-793, 2010

32. Simonini P, Breiling A, Gupta N, et al: Epigenetically deregulated microRNA-375 is involved in a positive feedback loop with estrogen receptor alpha in breast cancer cells. Cancer Res 70: 9175-9184, 2010

33. Yu L, Todd NW, Xing LX, et al: Early detection of lung adenocarcinoma in sputum by a panel of microRNA markers. Int J Cancer 127: 2870-2878, 2010.
34. Szczyrba J, Nolte E, Wach S, et al: Downregulation of Sec23A protein by miRNA-375 in prostate carcinoma. Mol Cancer Res 9: 791-800, 2011.

35. Baffa R, Fassan M, Volinia S, et al: MicroRNA expression profiling of human metastatic cancers identifies cancer gene targets. J Pathol 219: 214-221, 2009.

36. Davidson LA, Wang NY, Shah MS, Lupton JR, Ivanov I and Chapkin RS: n-3 Polyunsaturated fatty acids modulate carcinogen-directed non-coding microRNA signatures in rat colon. Carcinogenesis 30: 2077-2084, 2009.

37. Berg M, Agesen TH, Thiis-Evensen E, et al: Distinct high resolution genome profiles of early onset and late onset colorectal cancer integrated with gene expression data identify candidate susceptibility loci. Mol Cancer 9: 100, 2010. 